\title{
EL PROBLEMA DE LA TUBERCULOSIS
}

Preocupación predominante de los Poderes públicos han sido en todo tiempo los problemas higiénico-sanitarios. $\mathrm{Y}$ bien merece la pena esta preocupación, porque responde evidentemente a la aspiración más sentida por el individuo: vivir mucho y vivir bien, entendiendo como el ideal del bien vivir, vivir con salud; y porque además de esta aspiración individual de todos los tiempos los problemas sanitarios tienen repercusiones decisivas en otra serie de problemas de capital importancia para las naciones.

El nivel demográfico de un pueblo depende de dos factores, natalidad y mortalidad, en relación directa con la primera e inversa con la segunda. Sobre la natalidad, nuestra influencia es muy escasa, ya que sus fluctuaciones dependen de circunstancias que en su mayor parte se escapan a la acción de la Sanidad; en cambio, sobre la mortalidad nuestra acción a través de una organización sanitaria, cada día más perfecta y más científicamente orientada, puede ser de gran eficaciz, pues no hay duda de que si no está por ahora en nuestras manos el evitar gran número de enfermedades y de casos de muerte (ésta realmente nunca la evitaremos en un sentido absoluto, aunque sí podemos retardarla), en otras muchas ocasiones está en nuestras manos evitar enfermedades y defunciones. Contra estas enfermedades y muertes evitables dirigen su actuación la Higiene y la Sanidad.

La tuberculosis es, sin duda alguna, entre las enfermedades evitables, la que atrae preferentemente la átención de los sanitarios y cel w. bien expiicada si consideramos que no sólo es una de las que producen mayor número de defurciones fures $39.0 \mathrm{~g} 0$ cal'a año en Españal, sino que elige sus victimas entre $:-$ iciventud, o sea, cusndo el indivicuo está en el cisirvíte máximo ce la vida y cuanòo está cotado de las mejores ap̃îứes para protucir un trabajo ú̉il a sí 538 mismo y a la scciedad. De cada 100 derunciones que ceureen en 
nuestro pais, siete son producidas por la tuberculosis; $\mathrm{y}$ de cada 1.000 ciudadanos españoles, seis por lo menos son tuberculosos. Estas cifras, así escuetamente expuestas, indican ya por sí solas la gravedad del problema; pero esta gravedad sube de punto si pensamos en que todas estas defunciones y todos estos casos de enfermedad se dan, como hemos dicho, en las edades de máximo trabajo eficaz del individuo, hasta el extremo que de las 30.000 defunciones que en España produce este mal 18.000, o sea bastante más de la mitad (las tres quintas partes), ocurren entre los quince y los cuarenta y cinco años, y de modo muy especial entre los veinte y veinticinco años.

Existen, ciertamente, otras enfermedades que dan cifras parecidas o próximas, rara vez iguales a las de la tuberculosis, tales como las hemorragias y reblandecimientos cerebrales, las enfermedades del corazón, el cáncer y tumores malignos, las pulmonías y enfermedades agudas del aparato respiratorio y otras; pero estas dolencias, hoy por hoy, ordinariamente no entran en el grupo de las que llamamos evitables, y además producen sus bajas sobre todo en las edades extremas de la vida (en la infancia y en la vejez), de tal suerte, que desde el punto de vista social no tienen ni remotamente la trascendencia de la tuberculosis, que, como hemos dicho, afecta espec:almente a la juventud y madurez de la vida.

Prescindiendo de otras consiäeraciones de orden humanitario, mirando fríamente el problema sólo en su aspecto económico, fácilmente se comprende que la plaga tuberculosa produce cuantiosas pérdidas a una nación. Es muy difícil valorar una vida humana, pues su valor depende de circunstancias tales que forzosamente ha de oscilar entre límites amplísimos. Pero si, por ejemplo, tomamos como término de comparación lo que en España paga el Seguro Obligatorio de Viajeros por cada muerto en accidente $(40.000$ pesetas, sin distinción de profesión, sexo ni edad), deduciremos que nuestras 30.000 defunciones anuales por tuberculosis supondrán por lo menos una pérdida de 1.200 millones de pesetas. $\mathrm{Y}$ si a ello agregamos los gastos que cada enfermo origina y la disminución del rendimiento de su trabajo durante su larga y penosa enfermedad, llegaremos con facilidad a la cifra de $\mathbf{1 . 5 0 0}$ millones.

Por desgracia, hasta el presente no se conoce ningún remedio eficaz cue preserve de la infección, ni que cure la enfermedad una vez establecidz, a pesar de que en la tarea se hallan empeñadas las más preclaras inteligencias médicas del mundo; pero sí conocemos una serie de medidas que, bien dirigidas por medio de una organi- 539 
zación amplia y racional, permiten evitar un gran número de infecciones y curar cada día en mayor proporción casos de tuberculosis que no hace muchos años se consideraban fatalmente condenados a la muerte. Quiero esto decir que hoy la tuberculosis está en el grupo de las llamadas enfermedades evitables y curables. Pero para esto se necesita un mecanismo de lucha tan completo, complejo y costoso, que en el corto espacio de estas líneas ni siquiera es posible esbozar. Diremos solamente que para hacer en esta materia una labor eficaz es indispensable la acción conjunta de nuúltiples actividades, ya que además de los medios directos de lucha contra la tuberculosis (diagnóstico precoz y profilaxia a cargo de los dispensarios; aislamiento y tratamiento de enfermos en los sanatorios), es preciso apelar a medidas indirectas, combatiendo no sólo las causas determinantes, cino también las predisponentes y coadyuvantes de la enfermedad, pues está demostrada la influencia que en la tuberculosis juegan los problemas de la alimentación, la convivencia, las condiciones de trabajo, salarios, situación del pueblo y en general todo lo relacionado con la higiene pública y privada; de tal manera, que aun sin apelar a medios de lucha directa, solamente con el mejoramiento de las condiciones higiénicas y del nivel de vida de una nación, automáticamente disminuye el número y gravedad de los casos de tuberculosis.

En la casi totalidad de las naciones, la lucha antituberculosa está encomendada a organismos especiales, que con mayor o menor independencia y autonomía absorben la totalidad de la obra. En España este organismo es el Patronato Nacional Antituberculoso, que bajo la directa dependencia del Ministro de la Gobernación, ha acometido la empresa de dotar a nuestro país del número de sanatorios, dispensarios y demás instituciones necesarias, para que nos acerquemos en lo posible al ideal de que no exista ni un tuberculoso ignorado, ni uno necesitado de cama sanatorial que carezca de ella. Pero repitámoslo: toda esta obra será poco eficaz sin la ayuda decidida de todos los demás organismos estatales, provinciales y municipales y sin la colaboración de todos los ciudadanos.

La empresa supone gastos de gran consideración. No es fácil calcular en los momentos actuales lo que supondría una organización perfecta de lucha antituberculosa: no obstante, con arreglo a los precios de hoy, y tomando como término de comparación la magnífica organización italiana, no superada ni aún igualada en ningún otro país, podemos calcular que en España se necesitaría un gasto anual de 250 millones de pesetas. La cifra parecerá exorbitante; pero si 540 consideramos que Italia, con su organización, en pocos años dismi- 
nuy6 su tuberculosis en un 50 por 100 , y sin pensamos que no hay razón ninguna parạ que en España no podamos obtener el mismo resultado, deduciremos que estos 250 millones supondrían una magnífica inversión, pues obtendríamos el ahorro de 15.000 vidas anuales, jóvenes en su mayoría, que según el cálculo expuesto más arriba, supondría una ventaja económica de 750 millones de pesetas cada año.

Ahora bien: es indudable que el Estado no puede cargar por sí solo con un gasto de esta naturaleza. En ningún país del mundo sostiene el Estado por sí solo la lucha antituberculosa, que se nutre con recursos de muy diversa procedencia, entre los que destaca en primer lugar el producto de las primas del seguro obligatorio de asistencia contra la tuberculosis, bien independientemente del seguro general de enfermedad, como ocurre en Italia, bien formando parte del seguro total de enfermedad, como sucede en Alemania, Inglaterra y otros países.

En España se ha promulgado ya la Ley de seguro de enfermedad, y actualmente se estudian los reglamentos para su aplicación, que en plazo breve entrarán en vigor. Entonces, con las aportaciones del seguro y con la subvención del Estado, contará la lucha antituberculosa con los recursos necesarios para lo más importante de la obra. Pero es preciso no olvidar, como ya hemos dicho, que la empresa es de una amplitud y complejidad enormes, por lo que no podrán desentenderse del problema los organismos provinciales y municipales, que habrán de colaborar no sólo con las aportaciones econńmicas (en todo caso modestas) que se les exigiesen, sino principalísimamente con su decidida ayuda para resolver los variadísimos factores que de modo indirecto influyen de tan decisiva manera en la persistencia y propagación de tan terrible azote. 